\title{
Sciendo
}

HOLISTICA Vol 10, Issue 2, 2019, pp. 137-156

\section{Relationship between economic growth and SO2 emissions - based on the PSTR model}

\author{
Ke, WU, \\ Department of Economics, Shanghai University,Shanghai, China \\ Address: No.20, Chengzhong Rd., Jiading District, Shanghai, China \\ ccoco_wu@163.com
}

\begin{abstract}
In this paper, we used the panel smooth transition model (PSTR) to study the nonlinear relationship between sulfur dioxide emissions and economic growth in the three regions of China's eastern, middle and western regions, based on panel data from 31 provinces and autonomous regions in China from 2005 to 2017. And calculated the elasticity of the impact of total export-import volume and urbanization rate on emissions. The empirical results indicate that economic development and sulfur dioxide emissions are positively correlated in the three regions of East, Middle and West. In the eastern region, when the economic scale is lower than the threshold value, it has a negative impact on $\mathrm{SO} 2$ emissions; but when it is higher than the threshold value, it has a positive impact on SO2 emissions, and the smoothing rate between the two regime is slow. The per capita GDP in the middle and western regions is weakly positively correlated with SO2 emissions. When the economic scale reaches the threshold value, its positive impact on SO2 emissions will increase, and economic development will further increase emissions.
\end{abstract}

Keywords: Sulfur dioxide emissions; Economic growth; PSTR; Nonlinear

JEL Classification: D4

\section{Introduction}

Since the reform and opening-up, China's economic and social development has gone through an extraordinary glorious course of 40 years, and has achieved remarkable historical achievements and achieved unprecedented historical changes. After 40 years of rapid growth, China has become the world's second largest economy after the United States.

However, it is undeniable that the rapid advancement of technological progress and industrialization has greatly improved the material living standards 
of human beings. The impact of human activities on the environment is growing. And some regions have unilaterally pursued economic growth at the expense of the environment and resources, especially the rapid growth of the industrial economy has led to serious air pollution (Minghui Li et al., 2011). Sulfur dioxide is one of the major pollutants in the atmosphere and an important indicator of whether the atmosphere is contaminated.

There have been many serious incidents of sulfur dioxide damage in many cities around the world, causing many people to be poisoned or killed. The "London Smoke Incident" was caused by a large amount of sulfur dioxide in the air, which led to tragedy. It has become history, but its warnings are far-reaching. Air and water are essential for human survival. Sulfur dioxide in the exhaust gas poses a serious threat to human health and induces many respiratory diseases. Moreover, sulphur dioxide is very soluble in water and its harm is not easily transferred, and the consequences are borne by the emitting countries themselves (Zhaoli Zhang et al., 2012).

Sulfur dioxide is also an important source of acid rain, acid rain has brought serious impacts and damage to the earth's ecological environment and human society and economy.Studies have shown that acid rain has serious harm to human landscapes such as soil, water bodies, forests, buildings, places of interest and historical sites, which not only causes major economic losses, but also endangers human survival and development.

According to the website of China quality inspection, one third of China's land has been attacked by acid rain. China is a major coal-producing and coal-burning country in the world. The acid rain caused by sulfur dioxide discharged from coal has affected $40 \%$ of the national area of nearly 4 million square kilometers and is still expanding. Therefore, analyzing the relationship between economic growth and sulfur dioxide emissions is of practical significance for how to control sulfur dioxide pollution.

\section{Literature Review}

Some scholars have studied the relationship between economic growth and air pollution. Grossman and Krueger (1991) analyzed whether Nafta would worsen environmental pollution, and found an inverse $U$-shaped relationship between SO2 and smoke dust and suspended matter, and between SO2 and smoke dust and per capita GDP. And borrowing the relationship between income distribution and economic growth proposed by Simon Kuznets (1955), condensing what is called the "hypothesis of environmental kuznets curve" (EKC), that is, when a 
country When the level of economic development is low, the degree of environmental pollution is relatively light, but environmental pollution will increase with economic growth.

When the country's economic development reaches a certain level, its environmental pollution level will gradually slow down and the environmental quality will gradually improve. Nektarios Aslanidis (2006) analyzed the panel data of 48 states in the United States from 1929 to 1994 through the PSTR model and found that sulfur dioxide emissions rose steadily at a later stage of economic development and then steadily declined at high income levels. However, for nitrogen oxide emissions, environmental pressures tend to rise with economic growth and then slow down with further growth but do not decline. Anil Markandya (2006) analyzed the relationship between per capita GDP and sulfur emissions in 12 Western European countries over 150 years, as well as the impact of air pollution regulations on the shape of the income-pollution relationship. An inverted U-shaped relationship between per capita GDP and sulfur emissions has been found, and the estimated turning points in most countries are reasonable. In addition, environmental regulations have been found to reduce EKC, and they can also change the turning point of the curve.

Sudong Zhou et al. (2010) conducted an empirical study on the relationship between air pollution and total output value using industry panel data from 1996 to 2007 in Jiangsu Province. The results show that the three air pollutants change in the same direction as the total output value of enterprises, and the larger the total output value, the larger the amount of air pollution is; there are significant differences in air pollution emissions in different industries.

Shenxiang Xie et al. (2012) analyzed the relationship between China's economic growth, FDI investment patterns and sulfur dioxide emissions with the help of China's provincial panel data from 2003 to 2009. Studies have shown that the "environmental Kuznets curve" of economic growth does exist in China, and the "hypothesis of pollution haven" of FDI is not established during the sample period. The increase in FDI has a reduced effect on China's sulfur dioxide emissions as a whole. Tianying Mao et al. (2017) used the EKC model and decomposition analysis method to explore the relationship between industrial $\mathrm{SO} 2$ emissions and economic growth in Jiangsu Province from 2003 to 2015.

It is found that with the increase of industrial economy since 1986, the emission of industrial sulfur dioxide in Jiangsu Province has undergone the process of first increasing and then decreasing. Scale and technical effect are the two factors that influence the emission of industrial sulfur dioxide, especially the 
technical effect plays a dominant role in the realization of industrial sulfur dioxide emission reduction target. Bo Cheng et al. (2018) empirically examined the impact of economic growth on air pollution based on provincial panel data from 2002 to 2012, and examined the regulatory role of institutional environment on the relationship between economic growth and air pollution. The results show that the relationship between economic growth and regional air pollution is inverted U-shape; and the relationship between economic growth and air pollution emission is negatively regulated by public participation and environmental regulation.

Throughout the domestic and international literature, it is found that due to data acquisition problems, few literatures study the relationship between SO2 emissions and economic growth based on time series methods; many literatures on EKC, whether it is panel data model, spatial measurement model, or time series model all adopts quadratic or cubic type. In fact, the transcendental form is essentially linear.

It is controversial to apply the linear model to test nonlinear relationship. The PSTR model first tested the homogeneity of the data, and used LM, LMF, LRT and other statistics to test the linear hypothesis, and modified the model expression to eliminate the homogeneity of the data produced by EKC. Moreover, many models only consider the income when testing the EKC, without considering other control variables, there may be the problem of missing variables.

Based on this, we used the smooth transformation regression model to study the nonlinear change between $\mathrm{SO} 2$ emission and economic growth, adding total export-import volume and urbanization rate as control variables. It makes up for the shortage of previous studies using linear model to test the nonlinear relation and missing variable. And studied the relationship between $\mathrm{SO} 2$ emissions and economic growth from the perspective of time series, which helps to analyze the relationship between economic growth and pollution emissions from a dynamic perspective.

\section{Model}

The Smooth Transition Regression Model proposed by Teräsvirta (1994) is an extension of the Smooth Transition Autoregression Model proposed by Hansen (1999), both autoregressive models and other time series models can be applied. By setting a continuous transformation equation that allows variables to smoothly transition between different regimes (Gonzalez et al., 2005), the change in regression parameters is no longer a jump change, but a slow transition, more 
closely related to the meaning of real economy. The simplest PSTR model with two extreme regimes and a single transition function can be defined as:

$$
y_{i t}=\mu_{i}+\beta_{0} x_{i t}+\beta_{1} x_{i t} g\left(q_{i t} ; r, c\right)+\beta_{2} z_{i t}+u_{i t}
$$

Where: $i=1, . . N$ stand for the number of panel data individuals; $t=1, \ldots . T$ stand for the dimension of time. $\mathrm{x}_{\mathrm{it}}$ represents the explanatory variable, which is the logarithm of the annual per capita GDP of each province and municipality in China. $y_{i t}$ represents the explanatory variable, which is the logarithm of annual SO2 emissions in all provinces and municipalities in China. $q_{i t}$ is a conversion variable, which is the logarithm of per capita GDP of every province and municipality in China. $z_{\text {it }}$ represents other explanatory variables that may affect $\mathrm{SO} 2$ emissions, and the coefficients of these variables do not smoothly transform with the change of the conversion variables. $\mu_{i}$ represents the fixed individual effect. $u_{i t}$ is the residual term obey a normal distribution with a mean of 0 and a constant variance.

The transition function $\mathrm{g}\left(\mathrm{q}_{\mathrm{it}} ; \mathrm{r}, \mathrm{c}\right)$ is a continuous function of the observable variable $q_{i t}$. Its value is between $0-1,0$ and 1 indicate the two extreme regimes. The function $\mathrm{g}\left(\mathrm{q}_{\mathrm{it}} ; \mathrm{r}, \mathrm{c}\right)$ proposed by Granger (1993) and Teräsvirta (1994) can be expressed in the form of logistic:

$$
\begin{aligned}
g\left(q_{i t} ; \gamma, c\right)= & \left(1+\exp \left[-\gamma \prod_{j=1}^{m}\left(q_{i t}-c_{j}\right)\right]\right)^{-1} \\
& \gamma \geq 0 \text { 目 } \mathrm{c}_{\mathrm{m}} \geq \cdots \geq \mathrm{c}_{1} \geq \mathrm{c}_{0}
\end{aligned}
$$

Where $c=\left(c_{1}, \ldots c_{m}\right)$ is the location parameter of $m$, which is the threshold value, González et al. (2005) consider that the location parameter $c$ takes $m=1$ or $\mathrm{m}=2$ to be representative.

When $m=1$, the form of the transition function is monotonically increasing between 0 and 1 , as shown in figure 1: When qit changes from small to large, it corresponds to two extreme regimes, the explanatory variable coefficient is smoothly transformed between $\beta_{0}$ and $\beta_{0}+\beta_{1}$.

Where the coefficient is $\beta_{0}$ in low regime and $\beta_{0}+\beta_{1}$ in high regime. 
Figure 1. Transition Function when $\mathrm{m}=1$

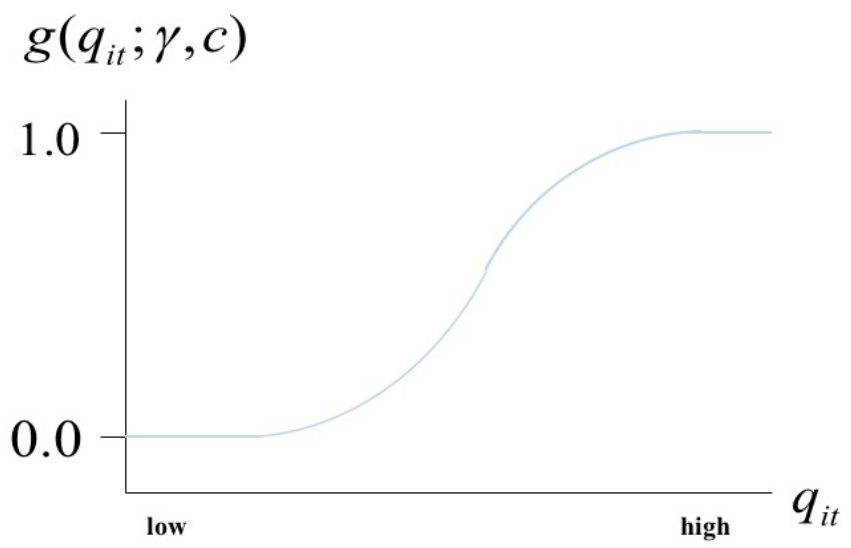

When $m=2$, it can be seen from Fig. 2 that the conversion function $g\left(q_{i t}, \gamma, c_{1}, c_{2}\right)$ takes the minimum value at $\left(c_{1}+c_{2}\right) / 2$, and the value ranges from 0 to 0.5 . When $q_{i t}$ is minimum and maximum, the conversion function are both 1 . then the model has three extreme mechanisms, it becomes a three-institutional model when $\gamma \rightarrow \infty$. the distribution on both sides is called the external regime, and the distribution in the middle is called the intermediate regime.

Figure 2. Transition Function when $\mathrm{m}=2$

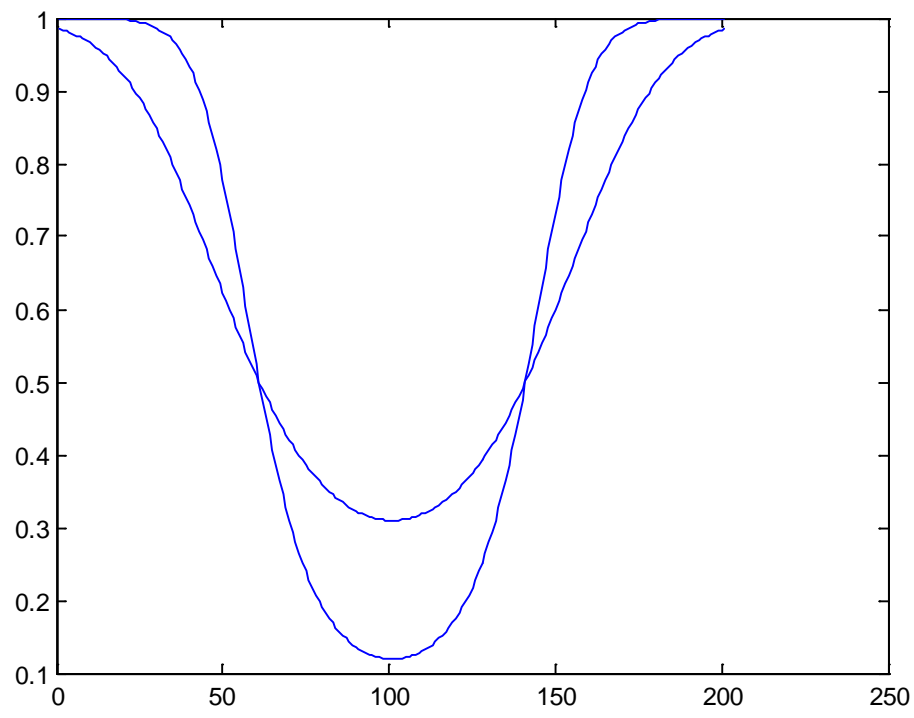


$\gamma>0$ is a smoothing parameter, controlling the speed of conversion function, the higher the value, the faster the conversion. If $\gamma \rightarrow \infty$, then the conversion speed is infinite, and the function has a discontinuity between the two extreme systems, the value of the conversion equation can only be 0 or 1 , and the model degenerates into Hansen's PTR model. If $\gamma=0$, the conversion equation degenerates into a homogeneous or linearly corrected panel regression.

The PSTR model setting process consists of three steps: The first step is to perform a linear verification of the model. Since the transformation equations in the model contain unknown parameters, here we refer to the method of Hansen (1996), replacing the transformation equation with a first-order Taylor formula. The model expression is converted to the following auxiliary regression equation:

$$
y_{i t}=\mu_{i}+\beta_{0}^{*} x_{i t}+\beta_{1}^{*} x_{i t} q_{i t}+\cdots+\beta_{m}^{*} x_{i t} q_{i t}^{m}+\beta_{m+1} z_{i t}+u_{i t}^{*}
$$

PSTR model constructs the parametric linear auxiliary regression equation, estimates the equation and the linear fixed-effects model respectively, and tests the statistic which is calculated according to the sum of their residual squares. The original hypothesis is $\mathrm{H}_{0}: \beta_{1}=\beta_{2}=\beta_{3}=0$, The corresponding assumptions are $\mathrm{H}_{01}^{*}: \beta_{1}^{*}=0\left|\beta_{3}^{*}=\beta_{2}^{*}=0, \mathrm{H}_{02}^{*}: \beta_{1}^{*}=0\right| \beta_{3}^{*}=0, \mathrm{H}_{03}^{*}: \beta_{3}^{*}=0$. We use TY chang's method to test the above hypothesis through Wald Tests, Fisher Tests, and LRT Tests. The statistics are LM, LMF and LRT, respectively. The expression is as follows:

$$
\begin{gathered}
\mathrm{LM}=\mathrm{NT}\left(\mathrm{SS} R_{0}-\mathrm{SS} R_{1}\right) / \mathrm{SS} R_{0} \\
\mathrm{LMF}=\left[\left(\mathrm{SS}_{0}-\mathrm{SS} R_{1}\right) /(\mathrm{mK})\right] /\left[\mathrm{SS} R_{1} / \mathrm{NT}-\mathrm{N}-\mathrm{m}(\mathrm{k}+1)\right] \\
\mathrm{LRT}=\mathrm{NT}\left[\log \left(\mathrm{SS} R_{0}\right)-\log \left(\mathrm{SS} R_{1}\right)\right]
\end{gathered}
$$

$\mathrm{SSR}_{0}$ and $\mathrm{SSR}_{1}$ are the sum of squared residuals for the original hypothesis and the alternative hypothesis, respectively, and $\mathrm{K}$ is the number of explanatory variables. The original hypothesis is accepted, the coefficients before the explanatory variables are all 0 , then the relationship between the them are linearly homogeneous. If the original hypothesis is rejected, the panel data has crosssectional heterogeneity, and there is a transition between different regimes in the model. The PSTR model can be used to continue to analyze. The results are different: when $\mathrm{H}_{01}{ }^{*}$ or $\mathrm{H}_{03}{ }^{*}$ is rejected, then $\mathrm{m}=1$; when $\mathrm{H}_{02}{ }^{*}$ is rejected, then $m=2$. 
After determining the value of $m$, the Nonlinear Least Squares estimate is used to get the parameter $\beta_{0}$ and $\beta 1, r, \gamma$ and $c$.

\section{Data}

\subsection{Basis for the division of $t^{\text {he Eastern, central and Western Regions }}$}

In this paper, according to the classification standards issued by the National Bureau of Statistics of the People's Republic of China in 2003, the mainland of China is divided into three economic regions: East, Middle and West according to the level of economic development and geographical location. However, in 2004, China carried out the western development strategy, and divided the two ethnic autonomous regions of Guangxi and Inner Mongolia into the western regions in the sense of national development.

Therefore, the Eastern region (11) includes Beijing, Tianjin, Hebei, Liaoning, Shanghai, Jiangsu, Zhejiang, Fujian, Shandong, Guangdong, and Hainan; the Middle region (8) is Shanxi, Jilin, Heilongjiang, Anhui, Jiangxi, Henan, and Hubei. Hunan; the Western region (12) includes Sichuan, Chongqing, Guizhou, Yunnan, Tibet, Shaanxi, Gansu, Qinghai, Ningxia, Xinjiang, Guangxi, and Inner Mongolia.

\subsection{Indicator selection and data description}

The main data of the empirical study is the Natural Logarithm of SO2 emission and the Natural logarithm of per capita income. Per capita income is usually expressed as per capita disposable income or per capita GDP, but setting only one exogenous variable in the econometrics can easily lead to large errors in the model. While taking into account the quantitative and data availability of other factors. This article joins the two indicators of total import-export volume and urbanization rate of each province or municipality.

According to the availability of the data, we compiled the data for each variable from 2005 to 2017. The explanation of each indicator is shown in Table 1. The data comes from the China Statistical Yearbook. Table 2 Table 3 Table 4 Table 5 describes the statistical characteristics of each variable in the model.

Table 1. Explanation of each indicator and unit description

\begin{tabular}{ccc}
\hline Variable & Definition & Unit of measurement \\
\hline SO2 emissions (SO2) & SO2 emission & 10 ton \\
GDP per capita (GDP) & GDP divided by the population & 10 yuan per capita \\
Trade & Total import and export & $10^{4}$ yuan \\
\hline
\end{tabular}


Table 2. Summary statistics of LnSO2

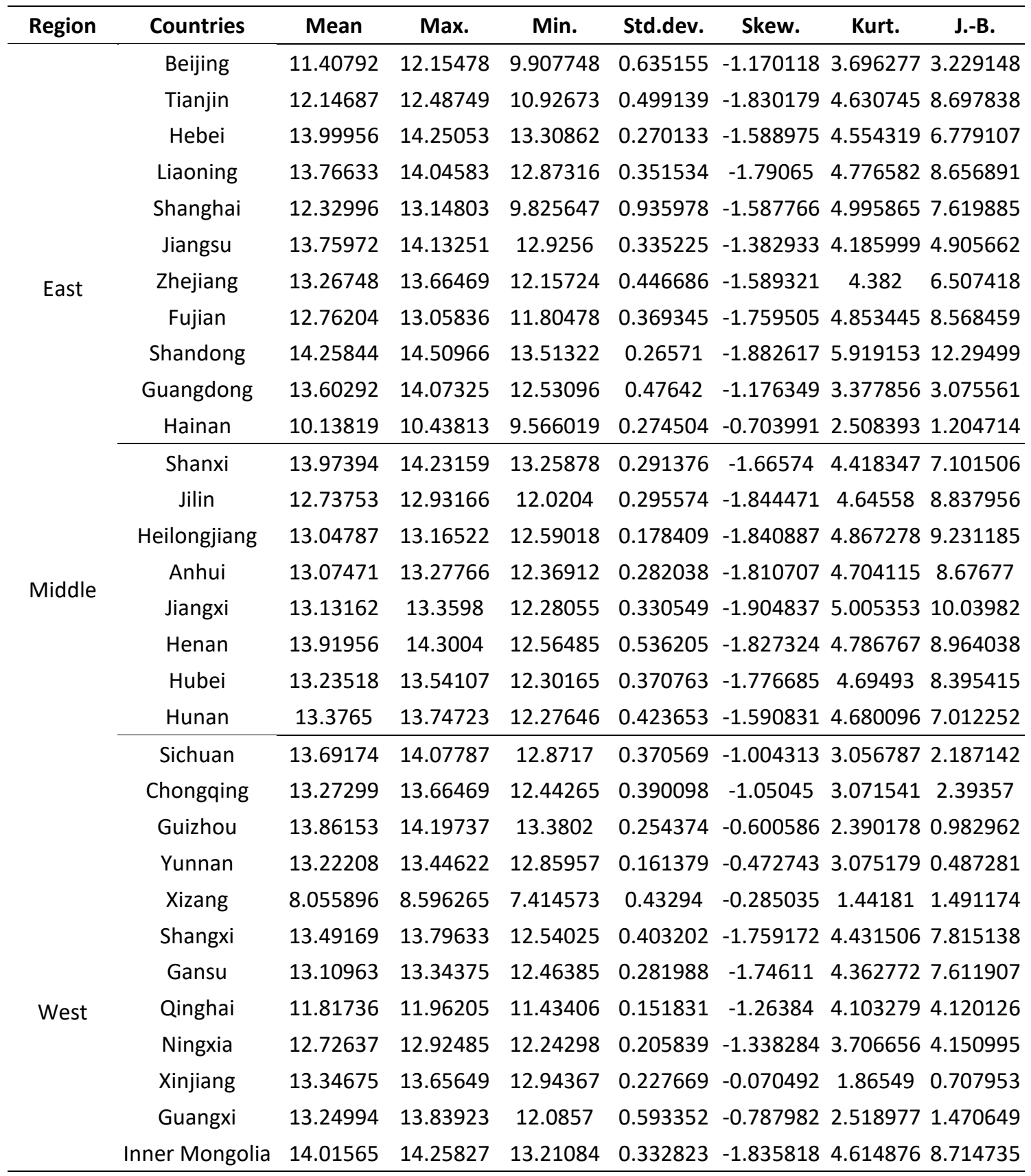


Note: 1. The sample period is from 2005 to 2017.

[?] indicates significance at the 0.01 level.

Table 3. Summary statistics of LnGDP

\begin{tabular}{|c|c|c|c|c|c|c|c|c|}
\hline Region & Countries & Mean & Max. & Min. & Std.dev. & Skew. & Kurt. & J.-B. \\
\hline \multirow{11}{*}{ East } & Beijing & 11.27824 & 11.76752 & 10.72424 & 0.324524 & -0.199913 & 2.002035 & 0.626056 \\
\hline & Tianjin & 11.22367 & 11.68641 & 10.48523 & 0.407948 & -0.545805 & 1.938147 & 1.256202 \\
\hline & Hebei & 10.28772 & 10.72298 & 9.601166 & 0.377438 & -0.55265 & 1.919696 & 1.293902 \\
\hline & Liaoning & 10.63124 & 11.08757 & 9.851299 & 0.423966 & -0.616897 & 2.014477 & 1.350649 \\
\hline & Shanghai & 11.29862 & 11.74906 & 10.84883 & 0.27472 & 0.023865 & 1.999413 & 0.543537 \\
\hline & Jiangsu & 10.93347 & 11.58199 & 10.10887 & 0.47973 & -0.330838 & 1.844717 & 0.960101 \\
\hline & Zhejiang & 10.8999 & 11.43016 & 10.2293 & 0.38733 & -0.317602 & 1.860707 & 0.921631 \\
\hline & Fujian & 10.66133 & 11.3227 & 9.833387 & 0.492481 & -0.319681 & 1.802176 & 0.998597 \\
\hline & Shandong & 10.66946 & 11.19557 & 9.908276 & 0.422685 & -0.447123 & 1.936976 & 1.045251 \\
\hline & Guangdong & 10.76877 & 11.30136 & 10.10377 & 0.375591 & -0.304925 & 1.97847 & 0.766697 \\
\hline & Hainan & 10.14519 & 10.78787 & 9.293854 & 0.502128 & -0.350543 & 1.752446 & 1.109287 \\
\hline \multirow{7}{*}{ Middle } & Shanxi & 10.16878 & 10.64685 & 9.433084 & 0.389529 & -0.678022 & 2.151111 & 1.386377 \\
\hline & Jilin & 10.39358 & 10.91214 & 9.499122 & 0.493085 & -0.570144 & 1.921776 & 1.334028 \\
\hline & Heilongjiang & 10.24205 & 10.64342 & 9.577342 & 0.378383 & -0.510973 & 1.764188 & 1.392952 \\
\hline & Anhui & 9.992663 & 10.67824 & 9.067624 & 0.547397 & -0.392105 & 1.747224 & 1.183234 \\
\hline & Jiangxi & 10.0297 & 10.67877 & 9.152711 & 0.515052 & -0.386451 & 1.805502 & 1.096444 \\
\hline & Henan & 10.15206 & 10.75094 & 9.336621 & 0.458457 & -0.416151 & 1.925416 & 1.000705 \\
\hline & Hubei & 10.29891 & 11.00541 & 9.344084 & 0.561422 & -0.385144 & 1.802125 & 1.098634 \\
\hline \multirow{12}{*}{ West } & Hunan & 10.16513 & 10.8109 & 9.252058 & 0.528679 & -0.439012 & 1.849134 & 1.135019 \\
\hline & Sichuan & 10.02745 & 10.70663 & 9.111624 & 0.531682 & -0.400204 & 1.807938 & 1.116735 \\
\hline & Chongqing & 10.3086 & 11.05788 & 9.304013 & 0.585449 & -0.39481 & 1.880361 & 1.016758 \\
\hline & Guizhou & 9.632586 & 10.54418 & 8.527539 & 0.668824 & -0.260939 & 1.815791 & 0.907133 \\
\hline & Yunnan & 9.787205 & 10.44059 & 8.966356 & 0.496163 & -0.27281 & 1.71581 & 1.054541 \\
\hline & Xizang & 9.882453 & 10.57814 & 9.117567 & 0.481813 & -0.103784 & 1.71732 & 0.914525 \\
\hline & Shangxi & 10.25311 & 10.95546 & 9.200189 & 0.584708 & -0.525629 & 1.947505 & 1.198649 \\
\hline & Gansu & 9.746307 & 10.25755 & 8.919587 & 0.465926 & -0.473006 & 1.81305 & 1.247885 \\
\hline & Qinghai & 10.13575 & 10.69301 & 9.21483 & 0.516792 & -0.514591 & 1.873506 & 1.261111 \\
\hline & Ningxia & 10.20962 & 10.83496 & 9.233959 & 0.541865 & -0.581739 & 1.973769 & 1.303701 \\
\hline & Xinjiang & 10.1968 & 10.71311 & 9.480978 & 0.428564 & -0.356929 & 1.645365 & 1.270007 \\
\hline & Guangxi & 9.969331 & 10.54802 & 9.081142 & 0.516828 & -0.42649 & 1.747148 & 1.244324 \\
\hline
\end{tabular}




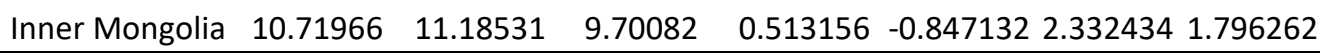

Note: 1 . The sample period is from 2005 to 2017.

[?] indicates significance at the 0.01 level.

Table 4. Summary statistics of LnTrade

\begin{tabular}{|c|c|c|c|c|c|c|c|c|}
\hline Region & Countries & Mean & Max. & Min. & Std.dev. & Skew. & Kurt. & J.-B. \\
\hline \multirow{11}{*}{ East } & Beijing & 19.05579 & 19.39782 & 18.4484 & 0.29963 & -0.634323 & 2.346946 & 1.102803 \\
\hline & Tianjin & 17.94056 & 18.2252 & 17.59064 & 0.217559 & -0.332466 & 1.825216 & 50.987054 \\
\hline & Hebei & 17.07964 & 17.4205 & 16.39302 & 0.341247 & -0.952011 & 2.48782 & 2.105797 \\
\hline & Liaoning & 17.80246 & 18.07676 & 17.32994 & 0.239433 & -0.625074 & 2.216539 & 1.179037 \\
\hline & Shanghai & 19.30608 & 19.58841 & 18.8436 & 0.222156 & -0.771198 & 2.452125 & 1.451208 \\
\hline & Jiangsu & 19.51243 & 19.80475 & 19.04505 & 0.221478 & -0.787808 & 2.534094 & 41.462301 \\
\hline & Zhejiang & 18.94667 & 19.35735 & 18.29251 & 0.318916 & -0.676383 & 2.350567 & 71.219692 \\
\hline & Fujian & 18.1716 & 18.56458 & 17.61262 & 0.346009 & -0.357425 & 1.469905 & 1.544943 \\
\hline & Shandong & 18.63556 & 18.9951 & 17.95642 & 0.336841 & -0.760545 & 2.274375 & 51.538465 \\
\hline & Guangdong & 18.1884 & 18.50831 & 17.57197 & 0.303418 & -0.692466 & 2.237804 & 41.353613 \\
\hline & Hainan & 15.47687 & 16.09217 & 14.54913 & 0.58943 & -0.457949 & 1.516797 & 71.645996 \\
\hline \multirow{8}{*}{ Middle } & Shanxi & 15.94755 & 16.26603 & 15.32906 & 0.292443 & -1.102853 & 2.841323 & 32.648919 \\
\hline & Jilin & 14.26264 & 14.78556 & 13.38898 & 0.452226 & -0.623243 & 2.228245 & 1.164223 \\
\hline & Heilongjiang & 14.60635 & 15.17394 & 13.77114 & 0.457797 & -0.105928 & 2.007123 & 0.558289 \\
\hline & Anhui & 16.73301 & 17.40496 & 15.82645 & 0.517038 & -0.335856 & 1.730144 & 1.117854 \\
\hline & Jiangxi & 16.4523 & 17.21756 & 15.01836 & 0.724959 & -0.697998 & 2.159329 & 1.438412 \\
\hline & Henan & 16.80474 & 17.77447 & 15.6605 & 0.779919 & -0.094525 & 1.366969 & 1.463871 \\
\hline & Hubei & 14.75629 & 15.34825 & 13.71622 & 0.545182 & -0.609396 & 2.057784 & 41.285498 \\
\hline & Hunan & 16.2408 & 17.00748 & 15.40784 & 0.504542 & -0.172772 & 1.783202 & 0.866665 \\
\hline \multirow{10}{*}{ West } & Sichuan & 16.91902 & 17.64403 & 15.68316 & 0.650723 & -0.62541 & 2.049591 & 11.336739 \\
\hline & Chongqing & 16.56852 & 17.88662 & 15.073 & 1.073427 & -0.111497 & 1.276097 & 71.636682 \\
\hline & Guizhou & 14.90577 & 15.84523 & 13.95507 & 0.635809 & -0.041664 & 1.662841 & 10.972258 \\
\hline & Yunnan & 16.07042 & 16.71623 & 15.17281 & 0.513067 & -0.359405 & 1.732374 & 1.150264 \\
\hline & Xizang & 13.2855 & 14.58631 & 12.03358 & 0.787361 & 0.283974 & 2.186123 & 3 0.53352 \\
\hline & Shangxi & 16.0537 & 17.11517 & 15.13706 & 0.639132 & 0.16916 & 1.77223 & 0.878517 \\
\hline & Gansu & 15.25057 & 15.6623 & 14.58314 & 0.32484 & -0.748165 & 2.475608 & 1.361744 \\
\hline & Qinghai & 13.32998 & 14.00188 & 12.73248 & 0.40646 & 0.334126 & 1.822093 & 30.99343 \\
\hline & Ningxia & 14.26934 & 15.03944 & 13.58205 & 0.467158 & 0.273352 & 2.137688 & 0.56467 \\
\hline & Xinjiang & 16.30542 & 16.65279 & 15.68802 & 0.310253 & -0.735424 & 2.488204 & 41.313719 \\
\hline
\end{tabular}


HOLISTICA Vol 10, Issue 2, 2019

\begin{tabular}{|c|c|c|c|c|c|c|c|c|}
\hline & Guangxi & 16.4679 & 17.46947 & 15.26114 & 0.71246 & $5 \quad-0.214689$ & 91.862322 & 0.80095 \\
\hline & Inner Mongolia & 15.69255 & 16.05439 & 15.20042 & 0.26339 & -0.46257 & 2.127762 & 0.875703 \\
\hline \multicolumn{9}{|c|}{$\begin{array}{l}\text { Note: } 1 . \text { The sample period is from } 2005 \text { to } 2017 . \\
\text { ?a? indicates significance at the } 0.01 \text { level. } \\
\text { Table 5. Summary statistics of URBR(\%) }\end{array}$} \\
\hline Region & Countries & Mean & Max. & Min. & Std.dev. & Skew. & Kurt. & J.-B. \\
\hline \multirow{11}{*}{ East } & Beijing & 158.3441 & 418.097 & 15.5708 & 121.4965 & 0.928257 & 2.893939 & 1.873027 \\
\hline & Tianjin & 79.7392 & 82.91586 & 75.07191 & 2.923403 & -0.369549 & 1.568638 & 1.405659 \\
\hline & Hebei & 45.87144 & 55 & 37.68793 & 5.459511 & 0.122747 & 1.969265 & 0.608119 \\
\hline & Liaoning & 63.44471 & 67.49828 & 58.70647 & 3.625045 & -0.13127 & 1.291997 & 1.617525 \\
\hline & Shanghai & 88.76733 & 89.60663 & 87.61905 & 0.682001 & -0.476366 & 1.968602 & 1.067886 \\
\hline & Jiangsu & 60.25579 & 68.76323 & 50.50079 & 6.383886 & -0.230781 & 1.571778 & 1.220297 \\
\hline & Zhejiang & 61.69307 & 68.00424 & 56.02084 & 4.215387 & -0.020245 & 1.558132 & 1.127004 \\
\hline & Fujian & 57.51316 & 64.79161 & 49.39556 & 5.239292 & -0.21827 & 1.682459 & 1.04351 \\
\hline & Shandong & 51.71065 & 60.58365 & 45.00433 & 5.082608 & 0.373809 & 1.899258 & 0.959055 \\
\hline & Guangdong & 65.93756 & 69.85406 & 60.68088 & 2.897922 & -0.326558 & 1.823129 & 0.981276 \\
\hline & Hainan & 51.07475 & 57.99136 & 45.16908 & 4.055101 & 0.238477 & 1.963163 & 0.705529 \\
\hline \multirow{8}{*}{ Middle } & Shanxi & 49.55093 & 57.34738 & 42.11624 & 5.231828 & 0.027491 & 1.610412 & 1.047572 \\
\hline & Jilin & 54.04384 & 56.64336 & 52.50368 & 1.270965 & 0.852322 & 2.480011 & 1.720442 \\
\hline & Heilongjiang & 56.40237 & 59.38242 & 53.08901 & 2.12859 & -0.104616 & 1.821078 & 0.776553 \\
\hline & Anhui & 44.70937 & 53.49321 & 35.50654 & 5.791745 & -0.067274 & 1.810711 & 0.775944 \\
\hline & Jiangxi & 45.82465 & 54.60839 & 36.99838 & 5.702497 & -0.004252 & 1.774506 & 0.813534 \\
\hline & Henan & 40.55433 & 50.16215 & 30.65032 & 6.228425 & -0.030595 & 1.832268 & 0.740643 \\
\hline & Hubei & 50.92111 & 59.30193 & 43.2049 & 5.861561 & -0.034267 & 1.470627 & 1.269492 \\
\hline & Hunan & 45.54439 & 54.62099 & 37.00601 & 5.414313 & 0.112765 & 1.98501 & 0.585578 \\
\hline \multirow{11}{*}{ West } & Sichuan & 41.80296 & 50.79499 & 33.00049 & 5.8243 & 0.000401 & 1.756437 & 0.83766 \\
\hline & Chongqing & 54.79562 & 64.09756 & 45.21086 & 6.2055 & -0.058605 & 1.736328 & 0.872411 \\
\hline & Guizhou & 35.14032 & 46.03352 & 26.86327 & 6.588372 & 0.234948 & 1.729096 & 0.994499 \\
\hline & Yunnan & 37.43203 & 46.67778 & 29.50562 & 5.726939 & 0.169661 & 1.702972 & 0.973603 \\
\hline & Xizang & 24.10394 & 30.86053 & 20.71429 & 3.341875 & 0.974092 & 2.536274 & 2.172332 \\
\hline & Shangxi & 47.34943 & 56.7927 & 37.23577 & 6.497571 & -0.077606 & 1.672742 & 0.967257 \\
\hline & Gansu & 37.68553 & 46.38233 & 30.01965 & 5.300421 & 0.147227 & 1.816635 & 0.805488 \\
\hline & Qinghai & 45.6132 & 53.01003 & 39.22652 & 4.928014 & -0.020277 & 1.55245 & 1.1359 \\
\hline & Ningxia & 49.54168 & 57.91789 & 42.28188 & 5.263644 & 0.122739 & 1.69267 & 0.95841 \\
\hline & Xinjiang & 43.06113 & 49.36605 & 37.16418 & 4.036892 & 0.039181 & 1.739661 & 0.863738 \\
\hline & Guangxi & 41.7229 & 49.21187 & 33.62661 & 5.194049 & -0.107108 & 1.729232 & 0.899567 \\
\hline
\end{tabular}


Note: 1. The sample period is from 2005 to 2017. [?]? indicates significance at the 0.01 level.

\section{Results}

\subsection{Nonlinear test and model form determination}

We use Matlab software programming to achieve the following model steps. In the PSTR model, the first step is to verify whether there is a conversion between different regimes in the panel data.

If the linear hypothesis is rejected, then the relationship is nonlinear, thus further determining the number of regimes, that is, the number of transformation equations. The results are shown in Table 6:

Table 6. Results of linearity tests

\begin{tabular}{cccc}
\hline Hypothesis & Region & Nonlinear test statistic & P-value \\
\hline & & Wald Tests (LM): 72.459 & 0 \\
& East & Fisher Tests (LMF) : 14.038 & 0 \\
& & LRT Tests (LRT):101.050 & 0 \\
H0: Linear Model & & Wald Tests (LM): 62.023 & 0 \\
H1: PSTR model with at least & Middle & Fisher Tests (LMF) : 14.283 & 0 \\
one Threshold Variable (r=1) & & LRT Tests (LRT):94.357 & 0 \\
& & Wald Tests (LM): 45.786 & 0 \\
& & Fisher Tests (LMF) : 6.231 & 0 \\
& West & LRT Tests (LRT): 54.200 & 0 \\
\hline
\end{tabular}

The statistical values of $P$ in the East, Middle and West are all 0 , which means that the original hypothesis is rejected on the significance level of $1 \%$. There is heterogeneity in the sample observation data, the model is nonlinear and there is at least one threshold value. This shows that the panel smooth transformation model can better describe the nonlinear characteristics of per capita GDP to SO2 emissions.

The second step of the model is to determine the form of the transformation equation, expand the transformation equation by first-order Taylor at $r=0$, and 
calculate the $\mathrm{F}$ statistics to test $H_{01}, H_{02}, H_{03}$ respectively, to determine the shape of the transformation equation. The results is shown in Table 7:

Table 7. Results of model tests

\begin{tabular}{cccc}
\hline Hypothesis & Region & F-statistic & m \\
\hline & & $F 3=3.003(0.003)$ & \\
& East & $F 2=2.757(0.006)$ & $\mathrm{m}=1$ \\
& & $\mathrm{~F} 1=5.569(5.569)$ & \\
$\mathrm{H}_{01}: \mathrm{B} 1=0 \mid \mathrm{B} 2=\mathrm{B} 3=0$. & $\mathrm{F} 3=2.119(0.036)$ & $\mathrm{m}=2$ \\
$\mathrm{H}_{02}: \mathrm{B2}=0 \mid \mathrm{B} 3=0$. & Middle & $\mathrm{F} 2=5.319(0.000)$ & \\
$\mathrm{H}_{03}: \mathrm{B3}=0$. & & $\mathrm{F} 1=3.375(0.001)$ & \\
& & $\mathrm{F} 3=0.366(0.949)$ & $\mathrm{m}=1$ \\
& West & $\mathrm{F} 2=1.127(0.348)$ & \\
\hline
\end{tabular}

Note: The $p$ value of the $F$ statistic in parentheses. 
According to the test results, the conversion equations in the east and west are logical, and the model only contains one location parameter; the conversion equation in the middle is exponential, and there are two location parameters in the model.

Secondly, determining the number of conversion intervals--r, that is, determining the number of conversion functions in the model. Three statistics methods of linear test are also used to test the original hypothesis $H_{0}: r=a$ and alternative hypothesis $H_{1}: r=a+1$.

If the original hypothesis can not be rejected, then the model contains a transformation equation, whereas the PSTR model contains at least $(a+1)$ transformation equation.

Then set the original hypothesis $H_{0}: r=a+1$ and the alternative hypothesis $H_{1}$ : $r=a+2$, and repeat the above process until all the statistics accept the original hypothesis. Where the value of $r$ is the number of transition functions of the model.

Table 8. Results of no remaining heterogeneity tests

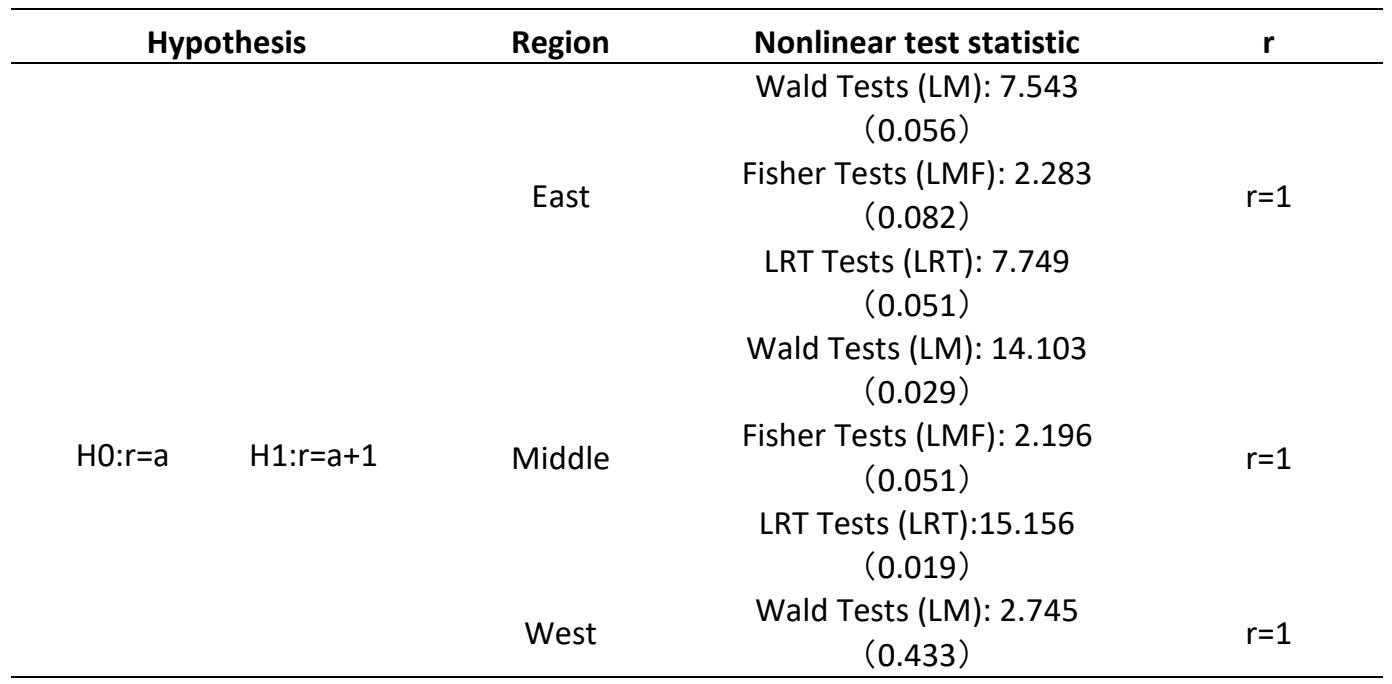


Fisher Tests (LMF) : 0.806

(0.493)

LRT Tests (LRT): 2.770

(0.429)

Note: The $p$ value of the $F$ statistic in parentheses.

The results in Table 8 show that the East, Middle and West models all accept the original assumption, $r$ is 1 , so there is no need to further test, the model only contains a conversion equation. Thus, the final form of the PSTR model for the East and West is determined as:

LNSO $_{i t}=\mu_{1}+\beta_{0} L N G D P_{i t}+\beta_{1} L_{N G D P}{ }_{i t} g\left(q_{i t} ; \gamma ; c\right)+\beta_{2} L_{N T r a d e} i t+\beta_{3} U_{R B R} R_{i t}+u_{i t}$

The final form of the PSTR model for the Middle is determined as:

LNSO $_{i t}=\mu_{1}+\beta_{0}$ LNGDP $_{\text {it }}+\beta_{1}$ LNGDP $_{\text {it }} g\left(q_{i t} ; \gamma ; c_{1} ; c_{2}\right)+\beta_{2}$ LNTrade $_{i t}+\beta_{3}$ URBR $_{i t}+u_{\text {it }}$

(9)

\subsection{Estimation of model parameters and results description}

In order to estimate the nonlinear transformation of the PSTR model, we use Nonlinear Least Squares (NLS).

The smoothing parameter $\gamma$ and the location parameter $\mathrm{c}$ are first determined and brought into the models to obtain the estimates value of other parameters. The estimated values of the parameters in the model of East, Middle and West are shown in the following table:

Table 9. Parameter estimates for the final PSTR models

\begin{tabular}{|c|c|c|c|c|c|c|}
\hline & \multicolumn{2}{|c|}{ East } & \multicolumn{2}{|c|}{ Middle } & \multicolumn{2}{|c|}{ West } \\
\hline & $\begin{array}{c}\text { LNGDP< - } \\
51.6579\end{array}$ & $\begin{array}{c}\text { LNGDP> - } \\
51.6579\end{array}$ & $\begin{array}{c}-1.2908 \\
\text { Or } \\
\text { LNGDP> } \\
0.0000\end{array}$ & $\begin{array}{c}0.0000 \\
>\text { LNGDP> } \\
-1.2908\end{array}$ & $\begin{array}{l}\text { LNGDP< } \\
10.1250\end{array}$ & $\begin{array}{l}\text { LNGDP> } \\
10.1250\end{array}$ \\
\hline$\beta_{\mathrm{GDP}}$ & -1.7861 & 1.7861 & 0.0014 & 1.1212 & 0.0509 & 0.7114 \\
\hline SD & 1.1786 & 1.2294 & 0.1225 & 0.7499 & 0.2187 & 0.0982 \\
\hline T-statistic & -1.5155 & 1.4529 & 0.0112 & 1.4951 & 0.2330 & $7.2459 * * *$ \\
\hline
\end{tabular}




\begin{tabular}{ccccccc}
\hline$\beta$ Trade & 0.0082 & -0.0082 & 0.2082 & -0.9696 & 0.0681 & -0.2282 \\
SD & 0.0147 & 0.0147 & 0.0609 & 0.2593 & 0.0616 & 0.0603 \\
T-statistic & 0.5549 & -0.5548 & $3.4172 * * *$ & $-3.7396 * * *$ & 1.1054 & $-3.7837^{* * *}$ \\
$\beta_{\text {URB }}$ & 0.0001 & -0.0001 & -0.0332 & 0.0190 & -0.0975 & -0.0524 \\
SD & 0.0009 & 0.0009 & 0.0115 & 0.0897 & 0.0142 & 0.0088 \\
T-statistic & 0.0922 & -0.0905 & $-2.8800 * * *$ & 0.2119 & $-6.8548 * * *$ & $-5.9639^{* *}$ \\
C & -51.6579 & & -1.2908 & 0.0000 & 10.1250 & $*$ \\
r & 0.1960 & & $6.0137 \mathrm{e}-07$ & & 2.2101 & \\
RSS & 10.022 & & 2.275 & & 5.861 & \\
\hline
\end{tabular}

Note: ${ }^{* * *}$ stand for $1 \%$ significant level.

in Table 9, the individual parameters passed the T-test in the model have economic explanatory significance. We can see that:

(1) The effect of economic growth on SO2 emission is different in East, Middle and West Regions. The emission of SO2 changes smoothly with per capita GDP between high and low regimes. Specifically, in the East region, the mechanism transition occurs when the location parameter of the model has a logarithm of 51.6579.

In the Middle region, the mechanism transition occurs when the location parameter of the model has a logarithm of -1.2908 and 0.0000 . Finally, in the West region, the mechanism conversion occurs when the location parameter of the model is 10.1250 .

The elasticity value of $\mathrm{SO} 2$ emissions is 0.0509 when the economic development is in a low regime, which is positively related. When the per capita GDP of the region gradually increases and is greater than this location parameter, the elasticity coefficient of emissions becomes 0.7114 , and economic development will be increase $\mathrm{SO} 2$ emissions to a certain extent.

(2) In the East, Middle and West provinces, the relationship between total export-import volume and $\mathrm{SO} 2$ emission is positive first and then negative.

(3) In the East provinces, the effect of urbanization rate on $\mathrm{SO} 2$ emission is positive first and then negative, while in the Middle and West provinces, the effect of urbanization rate on SO2 emission is just opposite to that in the East, it is negative first and then positive.

Figures 3, 4, and 5 show the transfer function images of the three models. The smoothing parameter $A$ determines the conversion speed between different 
economic regimes. It can be seen that the conversion speeds in the East and Middle regions are relatively slow, with $\gamma$ being 0.1960 and 6.0137e-07, respectively, while the $\gamma$ in West region is 2.2101. Therefore, there is obvious mechanism conversion characteristics. That is, after the economic development of the western cities reaches a certain scale, its effect on $\mathrm{SO} 2$ emissions will be smoothly converted from a high regime to a low regime; while the speed of transition between regimes in East and West region is slow.

Figure 3. Transition Function Plot of East

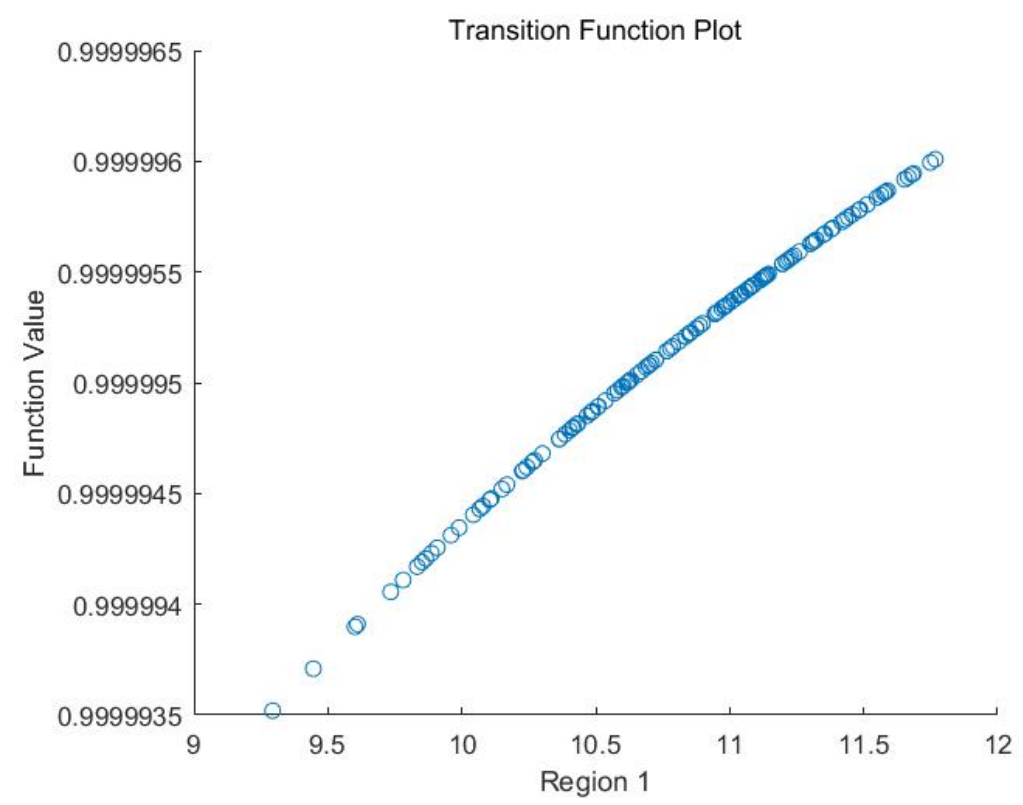

Figure 4. Transition Function Plot of Middle 


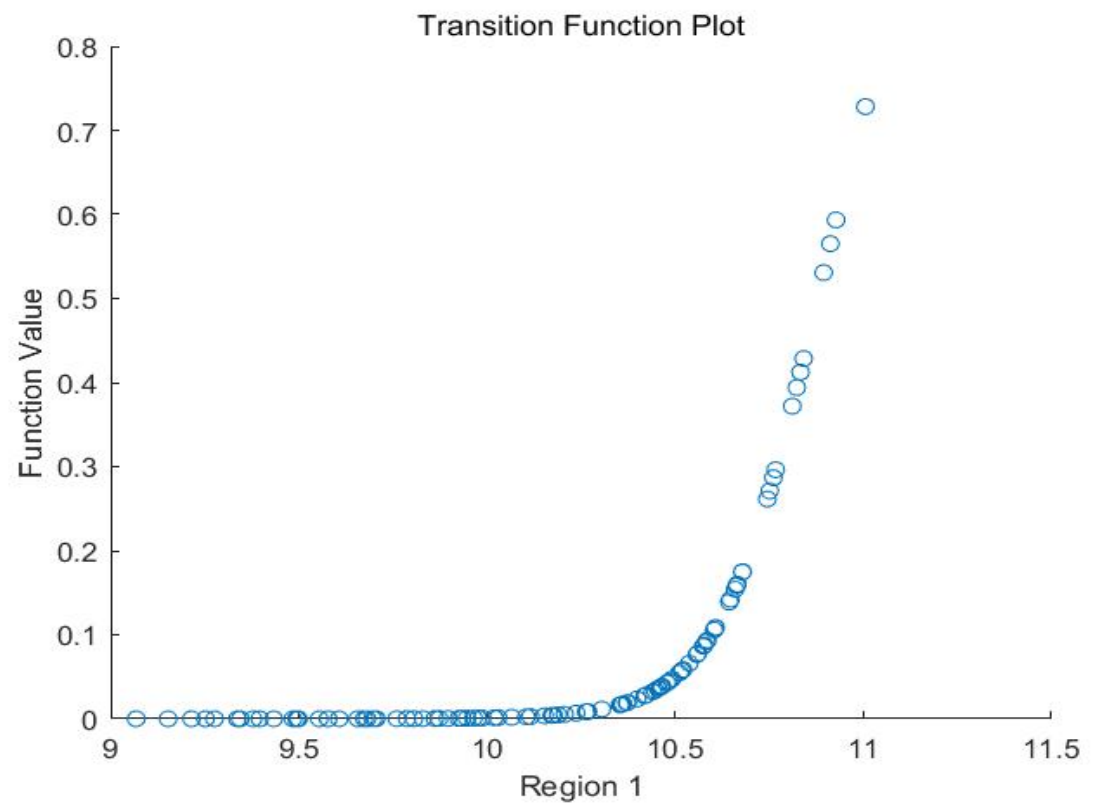

Figure 5. Transition Function Plot of West

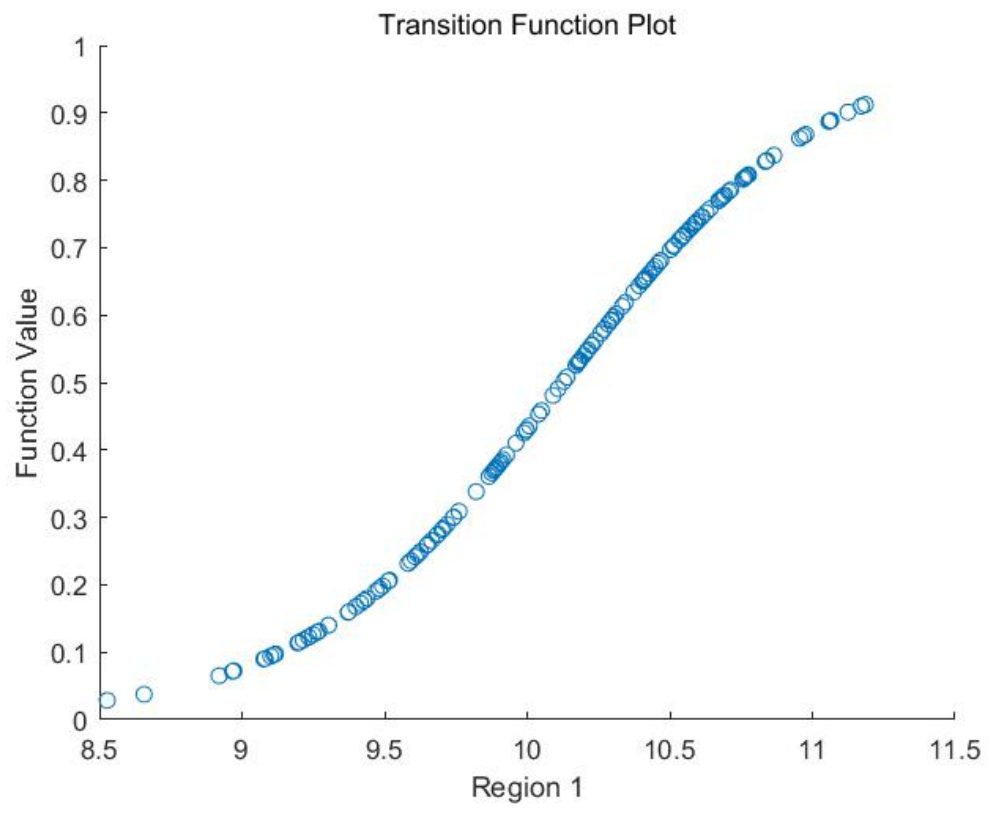




\section{Discussion, and Conclusions}

In this paper we have two main contributions. First, a nonlinear panel smooth transition regression (PSTR) model is constructed, which allows the regression coefficients to change gradually from one group to another.

That is, the parameters in the model can be changed continuously and gradually smoothly between different extreme regions with a function containing exogenous variable. This feature is consistent with the characteristics of changes in $\mathrm{SO} 2$ emissions. Its changes are not rapid and will change with the economic growth of a certain region, the total imports-exports volume, and urbanization rate gradually.

Secondly, based on the smooth transition regression model (PSTR) proposed by Gonzalez et al., the paper quantifies economic growth by using per capita GDP as the threshold variable. The model is firstly applied to analyze the effect of economic growth on $\mathrm{SO} 2$ emission in the three regions of East, Middle and West of China.

The results show that the situation in the East, Middle and West is different, but both indicate that there is a nonlinear vertical and horizontal smooth moving relationship, especially in the West.The Western region found that when per capita GDP is below the threshold value of per capita GDP of 24,959 yuan, per capita GDP is weakly positively correlated with $\mathrm{SO} 2$ emissions.

When the economic scale reaches the per capita GDP threshold value of per capita GDP of 24,959 yuan, its positive impact on the emission of $\mathrm{SO} 2$ will increase. Economic development has exacerbated emissions.

The natural carrying capacity of the western region is relatively weak. Along with the economic growth brought about by the government's policy of "China's Western Development Program", attention should also be paid to investment in the ecological field. For example, using the characteristics of geographical conditions to strengthen forestry development to reduce emissions, and actively developing wind energy, solar energy and other energy to improve the structure of traditional energy consumption, these will bring many economic and social benefits.

\section{References}

[1] Borghesi, S. (1999). The Environmental Kuznets Curve: A Survey of the Literature, FEEM Working Paper, No.85-99, pp. 1-29.

[2] Dinda, S. (2004). Environmental Kuznets curve hypothesis: A survey, Ecological Economics, (49), pp. 431-455. 
[3] Grossman, G. (1991). Krueger A B.Environmental impact of a North American free trade agreement, NBER Working Paper, No.3914.

[4] González, A., Teräsvirta, T., \& van Dijk, D. (20050. Panel smooth transition regression models.[J] Working Paper Series in Economics and Finance, No. 604.

[5] Hansen, B.E. (1999). Threshold effects in non-dynamic panels: estimation, testing, and inference. Journal of Econometrics, 93, pp. 334-368. Intergovernmental Panel on Climate Change, 2007. Climate change 2007. Fourth Assessment Report.

[6] Kuznets, S. (1955). Economic Growth and Income Equality, American Economic Review, 45(1), pp. 1-28.

[7] Minghui, L., Zhang, Y., \& Zhang, J. (2011). Review of Environmental Audit Abroad [ J ]. Audit and Economic Studies, 26(4), pp. 30-37.

[8] Panayotou, T. (1993). Empirical tests and policy analysis of environmental degradation at different stages of economic development, International Labour Office, Technology and Employment Programme, Working Paper.

[9] Talor, M.S., \& Brock, W.A. (2004). Economic Growth and the Environment: A Review of Theory and Empirics, NBER Working Paper No.10854, pp. 1-79.

[10] Zhang, Z., Zhou, Y. (2012). Air Pollution in China s economic growth and its international comparison -- taking sulfur dioxide as an example. Economic Management, 34(10), pp. 166174. 